\title{
Increased Probability of GABA Release during Withdrawal from Morphine
}

\author{
Antonello Bonci and John T. Williams \\ The Vollum Institute, L474, Oregon Health Sciences University, Portland, Oregon 97201
}

Opioid receptors located on interneurons in the ventral tegmental area (VTA) inhibit GABA $_{A}$-mediated synaptic transmission to dopamine projection neurons. The resulting disinhibition of dopamine cells in the VTA is thought to play a pivotal role in drug abuse; however, little is known about how this $\mathrm{GABA}_{A}$ synapse is affected after chronic morphine treatment. The regulation of GABA release during acute withdrawal from morphine was studied in slices from animals treated for 6-7 d with morphine. Slices containing the VTA were prepared and maintained in morphine-free solutions, and GABA $_{A}$ IPSCs were recorded from dopamine cells. The amplitude of evoked IPSCs and the frequency of spontaneous miniature IPSCs measured in slices from morphine-treated guinea pigs were greater than placebo-treated controls. In addition, activation of adenylyl

Chronic use of opioids results in tolerance to and dependence on the drug. One of the most widely accepted mechanisms for the cellular basis of tolerance is an uncoupling of the opioid receptor from the effector so that a greater receptor occupancy is required to obtain a given response (Law et al., 1982; Chavkin and Goldstein, 1984; Puttfarcken et al., 1988). Dependence is defined by a number of abnormal responses after the abrupt withdrawal of drug (Johnson and Flemming, 1989). The expression of dependence, or withdrawal, is thought to result from the development of adaptive changes that occur in the continued presence of agonist. The first adaptive response to be recognized at the cellular level was an upregulation of adenylyl cyclase (Sharma et al., 1975). Acutely, opioids inhibit the activity of adenylyl cyclase. However, in the continued presence of agonist the inhibition declined until the activity in the presence of agonist was not different from control. Adenylyl cyclase activity measured after the removal of opioid was increased above control. This rebound increase was thought to represent a cellular expression of opioid withdrawal. Much of what is known about the cellular basis for tolerance and dependence to opioids has come from studies on the opioid regulation of adenylyl cyclase in cell lines, although the cellular basis for the upregulation is not understood (Sharma et al., 1975; Law et al., 1982; Puttfarcken et al., 1988).

The electrophysiological approach has been used successfully to demonstrate tolerance to opioids; however, the cellular expression of withdrawal has been much more difficult to identify

Received Sept. 17, 1996; revised Oct. 29, 1996; accepted Oct. 31, 1996.

This work was supported by National Institutes of Health Grant DA08163. We thank MacDonald Christie, Jeffrey Diamond, and Matthew Jones for helpful discussions and comments.

Correspondence should be addressed to Dr. John T. Williams, The Vollum Institute, L474, Oregon Health Sciences University, 3181 SW Sam Jackson Park Road, Portland, OR 97201.

Copyright (C) 1997 Society for Neuroscience $\quad 0270-6474 / 97 / 170796-08 \$ 05.00 / 0$ cyclase, with forskolin, and cAMP-dependent protein kinase, with Sp-cAMPS, caused a larger increase in IPSCs in slices from morphine-treated animals. Conversely, the kinase inhibitors staurosporine and Rp-CPT-cAMPS decreased GABA IPSCs to a greater extent after drug treatment. The results indicate that the probability of GABA release was increased during withdrawal from chronic morphine treatment and that this effect resulted from an upregulation of the cAMP-dependent cascade. Increased transmitter release from opioid-sensitive synapses during acute withdrawal may be one adaptive mechanism that results from prolonged morphine treatment.

Key words: ventral tegmental area; dopamine; cAMP; A-kinase; $G A B A_{A}$; tolerance

(Christie et al., 1987; Wimpey et al., 1989; Kennedy and Henderson, 1991, 1992). In the locus coeruleus (LC), for example, tolerance to the opioid-induced inhibition in firing and the associated increase in potassium conductance has been demonstrated both in vivo and in vitro (Aghajanian, 1978; Christie et al., 1987). After withdrawal, however, the increased firing rate of LC neurons resulted primarily from augmented excitatory afferent drive (Tung et al., 1990; Akaoka and Aston-Jones, 1991).

The ventral tegmental area (VTA) is part of the endogenous reward circuit that is thought to be activated by many drugs of abuse, including opioids (Bozarth and Wise, 1981; Wise and Rompre, 1989). Within the VTA, GABA ${ }_{A}$-mediated IPSPs recorded in dopamine cells were thought to arise from excitation of local interneurons (Johnson and North, 1992a). As has been observed in many areas of the CNS, opioids directly inhibit these interneurons through activation of a potassium conductance (Nicoll et al., 1980; Madison and Nicoll, 1988; Wimpey and Chavkin, 1991; Johnson and North, 1992a). Thus, acute activation of opioid receptors within the VTA indirectly increased the activity of dopamine cells by removing GABA-mediated inhibition (Gysling and Wang, 1983). The purpose this study was to examine the $\mathrm{GABA}_{\mathrm{A}}$ IPSC during acute withdrawal from morphine and to identify potential second-messenger pathways that mediate altered function.

\section{MATERIALS AND METHODS}

Whole-cell recordings of membrane current were made from dopamine neurons in horizontal slices of guinea pig midbrain. Preparation of slices has been described previously (Cameron and Williams, 1994). Briefly, guinea pigs (300-400 gm) were anesthetized with halothane and killed. The midbrain was sliced $(250 \mu \mathrm{m})$ in the horizontal plane using a vibratome. Slices (up to 3 ) containing the VTA were stored before being placed in the recording chamber and superfused $(1.5 \mathrm{ml} / \mathrm{min})$ with warmed $\left(35^{\circ} \mathrm{C}\right) \mathrm{Krebs} /$ bicarbonate buffer containing the following (in $\mathrm{mm}$ ): $\mathrm{NaCl} 126, \mathrm{KCl} 2.5, \mathrm{NaH}_{2} \mathrm{PO}_{4} 1.2, \mathrm{MgCl}_{2} 1.2, \mathrm{CaCl}_{2}$ 2.4, glucose 11, 


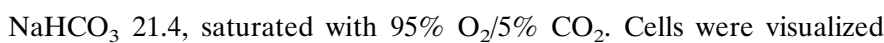
using an upright microscope with infrared illumination and recordings were made with whole-cell electrodes containing the following (mM): $\mathrm{KCl}$ 128, $\mathrm{NaCl} 20, \mathrm{MgCl}_{2}$ 1, EGTA 1, $\mathrm{CaCl}_{2}$ 0.3, Mg-ATP 2, GTP 0.25, buffered with HEPES 10, pH 7.3. Electrode resistance was 2-4 M $\Omega$, and acceptable access resistance was $<15 \mathrm{M} \Omega$, which was monitored periodically with repetitive $10 \mathrm{mV}$ steps $(20 \mathrm{msec}$ duration) from a holding potential of $-60 \mathrm{mV}$. Series resistance compensation of $\sim 80 \%$ was used during the entire experiment. Identification of dopamine cells was made based on the physiological properties, including a large $I_{\mathrm{h}}$-current (previously described by Johnson and North, 1992b). A monopolar glass stimulating electrode was placed near $(30-100 \mu \mathrm{m})$ the cell body. Neurons were voltage-clamped at a membrane potential of $-60 \mathrm{mV}$. Spontaneous IPSCs were recorded in the presence of TTX (300 nM) using PClamp (60 sweeps for each condition, $1 \mathrm{sec} / \mathrm{sweep}$ ), and miniature IPSC (mIPSC) amplitude was measured for each individual IPSC using Axograph 3.0. To determine accurately the IPSC amplitude, only IPSCs that were $>8 \mathrm{pA}$ were accepted for analysis. Results were plotted as cumulative amplitude and frequency histograms, and the effects of drugs were tested using the Komolgrov-Smirnov statistical method (Cohen et al., 1992); $p<0.05$ was taken as indicating statistical significance.

Drugs were applied in known concentrations to the superfusion medium. In experiments examining the $\mathrm{GABA}_{\mathrm{A}}$ synaptic potential, the superfusion medium contained 2-amino-5-phosphonopentanoic acid (AP5; $100 \mu \mathrm{M}$ ), 6-cyano-2,3-dihydroxy-7-nitro-quinoxaline (CNQX; 10 $\mu \mathrm{M})$, strychnine $(1 \mu \mathrm{M})$, and eticlopride $(100 \mathrm{nM})$ to block NMDA, AMPA, glycine, and dopamine $\mathrm{D}_{2}$-mediated synaptic currents, respectively. There was no effect of this solution on the holding current of the dopamine cells used in the present study. The same observation has been reported using this mixture of antagonists in guinea pig (Bonci and Williams, 1996) and rat VTA (Johnson and North, 1992b; Johnson et al., 1992). AP5 and picrotoxin were obtained from Sigma (St. Louis, MO). CNQX and eticlopride were obtained from Research Biochemicals (Natick, MA). Morphine (75 mg morphine/pellet obtained from National Institute on Drug Abuse) or placebo pellets (5 total) were implanted subcutaneously in anesthetized guinea pigs, one on day 1 and two on days 3 and 5. Experiments were carried out on days 6 and 7 .

Results in the text and figures were presented as the mean \pm SEM. Results between groups were compared using an unpaired $t$ test; $p<0.05$ was taken as indicating statistical significance.

\section{RESULTS}

Whole-cell recordings were made from dopamine cells in guinea pig brain slices that were identified as cells with a prominent hyperpolarization-induced inward current $\left(I_{\mathrm{h}}\right)$ when the holding potential was stepped from $-60 \mathrm{mV}$ to more negative potentials (Johnson and North, 1992b). Electrically evoked GABA IPSCs $_{\text {A }}$ were inward at a membrane potential of $-60 \mathrm{mV}$ and were completely blocked by picrotoxin $(100 \mu \mathrm{M})$. In all experiments, other synaptic currents were blocked with receptor antagonists (see Materials and Methods). Slices from both placebo- and morphine-treated animals were prepared and maintained in morphine-free solution. The opioid agonist normorphine depressed the amplitude of these $\mathrm{GABA}_{\mathrm{A}}$-mediated IPSCs (Fig. $1 A)$. In control, the $\mathrm{EC}_{50}$ of normorphine was $180 \pm 83 \mathrm{~nm}$ and the peak inhibition was $83 \pm 8 \%(n=4)$. After chronic morphine treatment, the normorphine-induced inhibition of IPSCs had an $\mathrm{EC}_{50}$ of $380 \pm 60 \mathrm{nM}$ and the peak inhibition was $70 \pm 3 \%(n=$ 4). These initial experiments demonstrate that this commonly used treatment protocol was sufficient to cause some tolerance to opioids in the VTA.

\section{Morphine withdrawal augments GABA release}

All experiments were carried out in morphine-free solutions at least $1 \mathrm{hr}$ and as long as $8 \mathrm{hr}$ after preparation of the brain slice. Characterization of GABA release after withdrawal from chronic morphine treatment was studied using two methods. The first method used a paired-pulse protocol, in which two stimuli were applied at an interval of $50 \mathrm{msec}$. In slices from the placebo- treated group, the second pulse evoked an IPSC that was generally larger than the first pulse (Fig. $1 B$ ). That is, facilitation of transmitter release was observed in $78 \%$ of cells in control ( $\mathrm{s} 2 /$ $\mathrm{s} 1=1.18 \pm 0.07, n=41)$. In morphine-withdrawn slices, the second stimulus evoked a smaller IPSC in $80 \%$ of cells tested (s2/s1 $=0.60 \pm 0.14, n=41)$. Thus, during morphine withdrawal the paired-pulse protocol resulted in depression. The numbers of cells showing facilitation and depression using the paired-pulse protocol are illustrated in Figure $1 C$ and indicate that depression was observed most often during morphine withdrawal. Facilitation or depression was not dependent on the size of the initial IPSC (Fig. $1 B$ ) and was not affected by changing the stimulus intensity (Fig. 1D). Manipulations that increase transmitter release in many sites have been found to result in a shift in the paired-pulse ratio toward depression (Mennerick and Zorumski, 1995; Salin et al., 1996). The present results suggest that the probability of GABA release was augmented during morphine withdrawal. Paired-pulse depression during morphine withdrawal was relatively persistent, because it was observed in slices as early as $1 \mathrm{hr}$ and up to $8 \mathrm{hr}$ after the slice was placed in morphine-free solution.

One possible explanation for the depression found during morphine withdrawal was that the $\mathrm{GABA}_{\mathrm{A}}$ receptors may be more likely to desensitize. Direct application of GABA using iontophoresis was used as a postsynaptic control to test this possibility. GABA (50-150 nA) was applied at a distance of 3-10 $\mu \mathrm{m}$ from the dopamine cell body. Two pulses of GABA (10-20 msec) were applied $100 \mathrm{msec}$ apart. The amplitude of the inward current among different cells ranged from $27 \mathrm{pA}$ to $4 \mathrm{nA}$, and the duration ranged from 50 to $100 \mathrm{msec}$. There was no consistent difference between the amplitude of the first and second pulses in slices from morphine-treated animals ( $n=5$, data not shown).

The frequency and amplitude of spontaneous mIPSCs (in 500 nM TTX) comprised the second method used to identify altered regulation of GABA release during morphine withdrawal. The rate of spontaneous mIPSCs was significantly greater in morphine-withdrawn slices [control, $2.4 \pm 1.3 \mathrm{~Hz}(n=8)$; morphine-withdrawn, $9.3 \pm 2.8 \mathrm{~Hz}(n=7, p<0.05)]$. There was no significant difference in the amplitude distribution of spontaneous mIPSCs in the two groups. The mean amplitude of spontaneous mIPSCs was $36.4 \pm 2.8 \mathrm{pA}$ in control and $35.6 \pm 4.1$ in morphine-withdrawn slices. Therefore, both the paired-pulse protocol and the increase in frequency of spontaneous events suggested that the probability of GABA release in the VTA was increased during withdrawal from morphine.

It was possible that the difference in GABA release between the two groups of animals resulted indirectly from activation of presynaptic receptors in response to a second transmitter. Potential candidates include GABA itself, adenosine, and 5-HT, all of which are present and have been shown to cause potent presynaptic inhibition of GABA release (Johnson et al., 1992; Wu et al., 1995). The amplitude of the IPSC (S1) was measured in the presence of both the $\mathrm{GABA}_{\mathrm{B}}$ receptor antagonist CGP35348 (100 $\mu \mathrm{M})$ and the A1 antagonist DPCPX (1 $\mu \mathrm{M})$. In DPCPX, the amplitude of the IPSC was increased in both groups of animals to the same extent $[11 \pm 7.8 \%$ in control $(n=7)$ and $12.3 \pm 7.3$ in morphine-withdrawn slices $(n=7)]$. The IPSC was not affected by CGP35348 (control, $n=3$; morphine-withdrawn, $n=4$ ). Although 5-HT caused a potent presynaptic inhibition of the $\mathrm{GABA}_{\mathrm{B}}$ IPSP, it had no effect on the GABA $\mathrm{A}$ IPSP in rat (Johnson et al., 1992). There was no effect of the nonselective 5-HT $\mathrm{H}_{1}$ agonist 5-CT $(1 \mu \mathrm{M})$ on the $\mathrm{GABA}_{\mathrm{A}}$ IPSC in slices from control and morphine-treated guinea pigs ( $n=5$ for each group). 

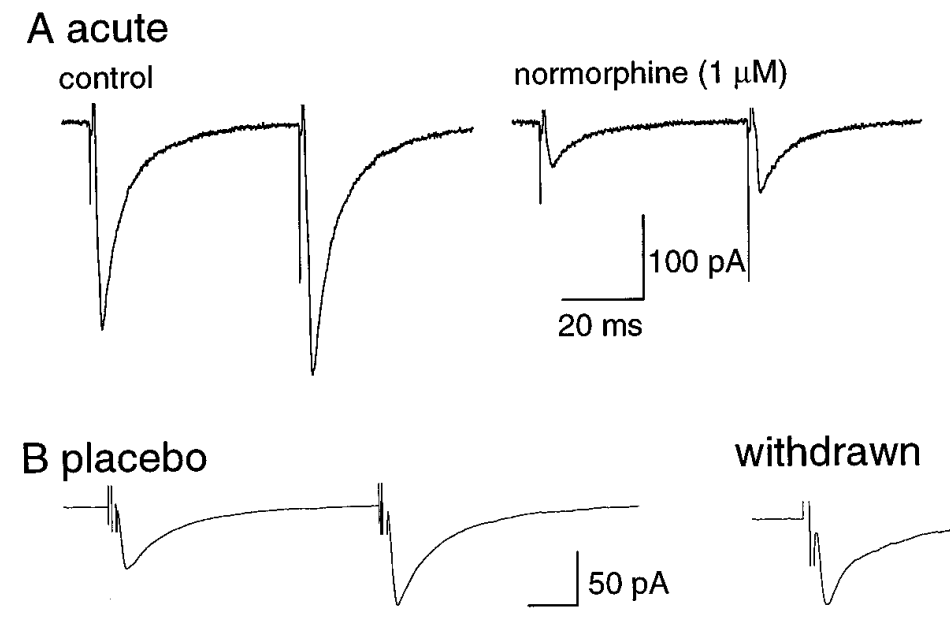

withdrawn
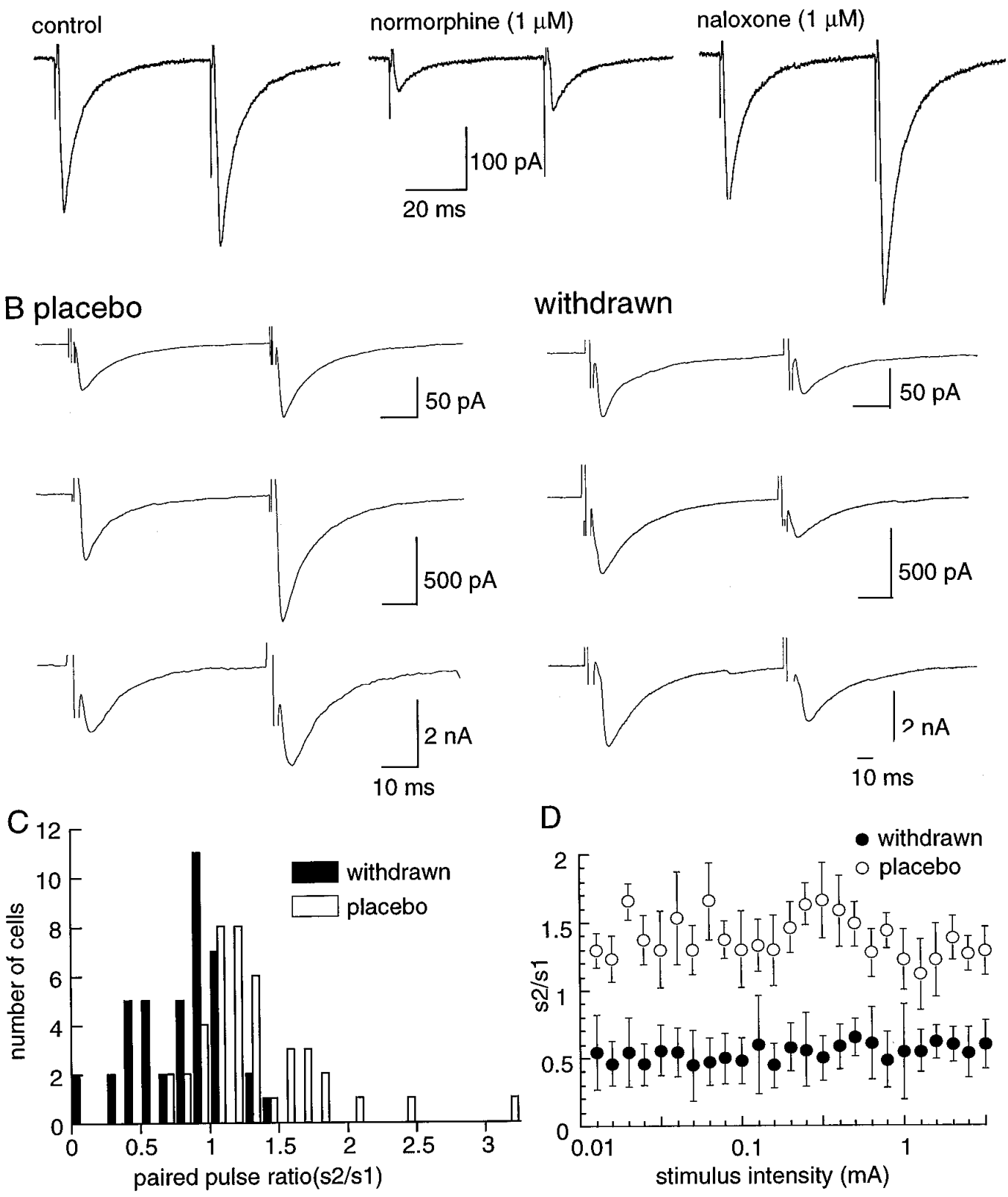

Figure 1. IPSCs from morphine-treated animals show paired-pulse depression, unlike those from controls, which show paired-pulse facilitation. $A$, Recording of GABA ${ }_{\mathrm{A}}$-mediated IPSCs from a control slice using the paired-pulse protocol (left trace). Normorphine $(1 \mu \mathrm{M})$ depressed the IPSC (middle trace), and that inhibition was reversed by the addition of naloxone to the normorphine-containing solution (right trace). $B$, Examples from three different cells in slices from both placebo- and morphine-treated animals. $C$, Cumulative results showing the distribution of paired-pulse ratio for many cells in slices from placebo $(n=41)$ - and morphine $(n=41)$-withdrawn slices. $D$, The paired-pulse ratio is independent of the stimulus strength. These results are the average from four cells in each group of animals.

Because the amplitude of the IPSC was not selectively affected by any of these manipulations in cells from morphine-withdrawn slices, the results suggest that the increase in GABA $_{A}$ IPSC observed in morphine-treated animals did not result from altered sensitivity to endogenous adenosine, GABA, or 5-HT.

\section{cAMP-dependent modulation of GABA release}

It has been known for many years that chronic morphine treatment augments adenylyl cyclase activity in cell lines and various parts of the CNS (Johnson and Flemming, 1989). In addition, forskolin stimulation of adenylyl cyclase has been shown to in- crease release of both GABA and glutamate in a variety of preparations including the VTA (Cameron and Williams, 1993; Rosenmund et al., 1994; Bonci and Williams, 1996; Salin et al., 1996). Forskolin produced a concentration-dependent increase in the amplitude of the $\mathrm{GABA}_{\mathrm{A}}$ IPSC in both control and morphinewithdrawn slices (Fig. 2). The forskolin-induced increase in morphine-withdrawn slices was significantly larger and longer lasting than that in controls (Fig. $2 B, C$ ). The sensitivity to forskolin was not changed, but the maximum effect was increased $\left(\mathrm{EC}_{50} 1.8 \mu \mathrm{M}\right.$ in control, $1.5 \mu \mathrm{M}$ in withdrawn slices, maximum 

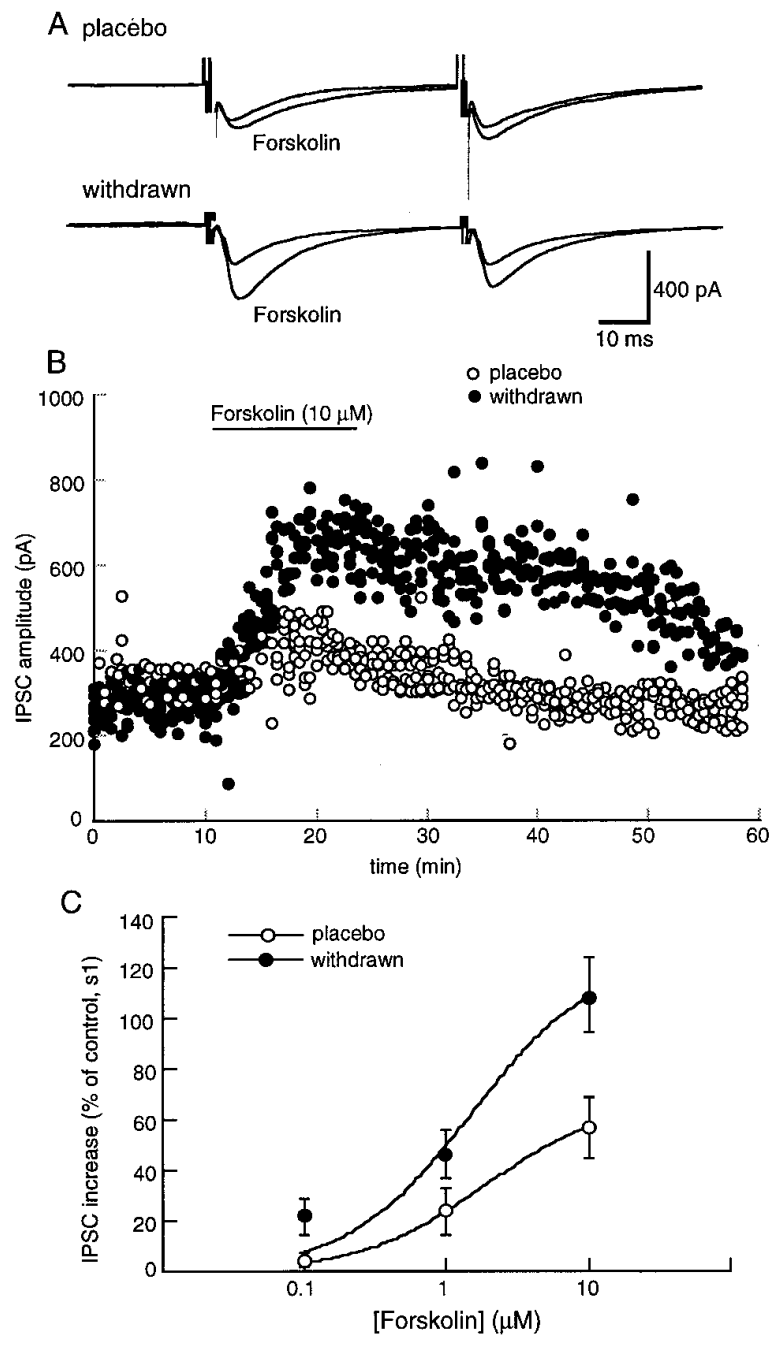

Figure 2. Forskolin augments the IPSC. This augmentation is significantly larger in morphine-withdrawn slices than in the placebo controls $(p<0.05)$. $A$, Examples of experiments from placebo- and morphinetreated animals. $B$, The amplitude of the first IPSC is plotted as a function of time in cells from placebo (open circles)- and morphine (solid circles)withdrawn slices. Results are from four slices for each group. Forskolin (10 $\mu \mathrm{M})$ increased the amplitude of the IPSC to a greater extent and for a more prolonged period in morphine-withdrawn slices than in controls. $C$, The concentration response to forskolin. The amplitude of the first IPSC in the paired-pulse protocol is plotted as a function of the concentration of forskolin. The amplitude was normalized against the mean of the first 10 IPSCs for each cell. Results were obtained from four cells from four different animals in each group. The data were fit with a least-squares regression from a logistic equation and gave estimates of the $\mathrm{EC}_{50}$ and maximum effect of forskolin of $1.8 \mu \mathrm{M}$ and $66 \%$ increase in control and 1.5 $\mu \mathrm{M}$ and $125 \%$ increase in morphine-withdrawn slices.

augmentation $66 \%$ in control and $125 \%$ in withdrawn slices; Fig. $2 C)$. The inactive analog of forskolin, dideoxyforskolin $(10 \mu \mathrm{M})$, had no significant effect on the IPSC (percent change from control, $4.3 \pm 5.1 \%$ in placebo, $5.1 \pm 6.2$ in morphine-withdrawn, $n=$ 4 cells each).

The frequency of spontaneous mIPSCs was also significantly increased by forskolin $(10 \mu \mathrm{M})$ in morphine-withdrawn slices (from $9.3 \pm 2.8$ to $23.6 \pm 3.5 \mathrm{~Hz}, n=7$ ) animals as compared to controls $(2.4 \pm 1.3$ to $3.2 \pm 1.2 \mathrm{~Hz}, n=8$; Fig. 3$)$. There was no significant difference in the amplitude of the mIPSCs in the absence and presence of forskolin in slices from either group of animals. In slices from control animals the mean amplitude was $36.4 \pm 2.8 \mathrm{pA}$ in control and $37.9 \pm 4.3 \mathrm{pA}$ in forskolin $(10 \mu \mathrm{M})$, and in slices from morphine-withdrawn animals the mean amplitude was $35.6 \pm 4.1 \mathrm{pA}$ in control and $34.4 \pm 3.2 \mathrm{pA}$ in forskolin. An upregulation of adenylyl cyclase could account for the increase in probability of GABA release as determined by the depression of the paired-pulse ratio and the increase in spontaneous mIPSCs in morphine-withdrawn slices.

\section{Kinase-dependent modulation of GABA release}

Superfusion with the cAMP analog Sp-cAMPS (100 $\mu \mathrm{M}, 15 \mathrm{~min})$ had little or no effect on the amplitude of the IPSC $(9.2 \pm 3.7 \%$, $n=3$; Fig. 4); however, the same protocol caused a significant augmentation in the IPSC amplitude in withdrawn slices (46 \pm $11 \%, n=3, p<0.05$; Fig. 4). This experiment suggested that the forskolin-induced increase in GABA $_{\mathrm{A}}$ IPSCs may involve cAMPdependent kinase.

The nonselective kinase inhibitor staurosporine (300 nM) caused a decrease of $45 \pm 4.3 \%(n=4)$ in the amplitude of the IPSC in morphine-withdrawn slices. This inhibition was larger than that found in slices from control animals $(26 \pm 4.3 \%$ of control, $n=4, p<0.05$; Fig. 5). The ratio of IPSC amplitudes found using the paired-pulse protocol was not changed by staurosporine in control $(1.41 \pm 0.1$ in control to $1.42 \pm 0.2$ in staurosporine, $n=4)$ but was increased in withdrawn slices $(0.58 \pm 0.07$ in control, $1.66 \pm 0.2$ in staurosporine). In addition, the frequency but not the amplitude of spontaneous IPSCs was also decreased by staurosporine, an effect that was significantly greater in withdrawn slices (from $8.9 \pm 1.8 \mathrm{~Hz}$ in control to $2.7 \pm$ $0.8 \mathrm{~Hz}$ in staurosporine, $n=6$ ) than in controls (from $2.1 \pm 0.3 \mathrm{~Hz}$ in control to $2.0 \pm 0.4 \mathrm{~Hz}$ in staurosporine, $n=6$; Fig. 6). Finally, the forskolin-induced increase in IPSCs was blocked by pretreatment with staurosporine (Fig. 5).

To characterize further the kinase involved in the regulation of GABA release, Rp-CPT-cAMPS, a relatively selective blocker of cAMP-dependent kinase, was used. Superfusion with Rp-CPTcAMPS $(100 \mu \mathrm{M})$ significantly reduced the amplitude of the IPSC $(p<0.05$; Fig. 5), blocked the effect of forskolin (Fig. 5), and caused a shift of the paired-pulse ratio toward facilitation in morphine-withdrawn slices (s2/s1 from $0.6 \pm 0.2$ to $1.25 \pm 0.2, n=$ $3)$. The same protocol had no effect in slices from control animals ( $\mathrm{s} 2 / \mathrm{s} 1$ from $1.41 \pm 0.03$ to $1.42 \pm 0.1, n=3$ ). These observations suggest that the activity of cAMP-dependent kinase was higher in morphine-withdrawn slices from drug-treated animals than in controls and that the increased activity was responsible for the augmented GABA release.

The augmentation of IPSCs induced by phorbol dibutyrate (PDBU; $300 \mathrm{nM}$ ), a phorbol ester, was examined in slices from control and morphine-treated animals as a test for the selectivity of the cAMP-dependent augmentation of GABA release. Although PDBU increased the amplitude of the IPSC in both groups [control $38.5 \pm 4.3 \%(n=4)$, morphine $44.8 \pm 6.7 \%(n=3)$ ], the augmentation was the same in each. A small depression of the paired-pulse ratio (s2/s1) was caused by PDBU in each group [control from $1.39 \pm 0.1$ to $0.9 \pm 0.1(n=4)$, morphine-withdrawn from $0.6 \pm 0.18$ to $0.55 \pm 0.04(n=3)]$. Thus, it appeared that the augmentation of transmitter release during morphine withdrawal may be mediated selectively through a cAMP-dependent pathway.

Experiments aimed at further identification of sites in the cAMP cascade that were affected by morphine withdrawal were inconclusive. The adenylyl cyclase inhibitor SQ22356 (300 $\mu \mathrm{M}$ to 1 $\mathrm{mM}$ ) was tested in an attempt to determine whether the basal level 
Figure 3. Forskolin increased the frequency of spontaneous mIPSCs to a greater extent in morphine-withdrawn slices than in placebo controls. $A$, Experiment from a cell in a slice from a control animal. Top traces show the occurrence of spontaneous IPSCs in control (left) and after superfusion with forskolin $(10 \mu \mathrm{M}$, right $)$. The three plots below the traces show an amplitude histogram (left), a cumulative probability plot of the amplitude (middle), and a cumulative probability plot of the frequency of spontaneous IPSCs from the same cell shown above. In this particular cell, forskolin had little effect on the rate and amplitude of the spontaneous IPSCs. $B$, Illustration of the same experiment in a cell recorded in a slice taken from a morphine-treated animal. The initial rate of activity was higher, and forskolin induced a significant increase in the rate of spontaneous IPSCs $(p<0.05)$. All experiments were carried out in the presence of TTX (500 nM), CNQX $(10 \mu \mathrm{M})$, APV $(100 \mu \mathrm{M})$, strychnine (1 $\mu \mathrm{M})$, and eticlopride (100 $\mathrm{nm})$.

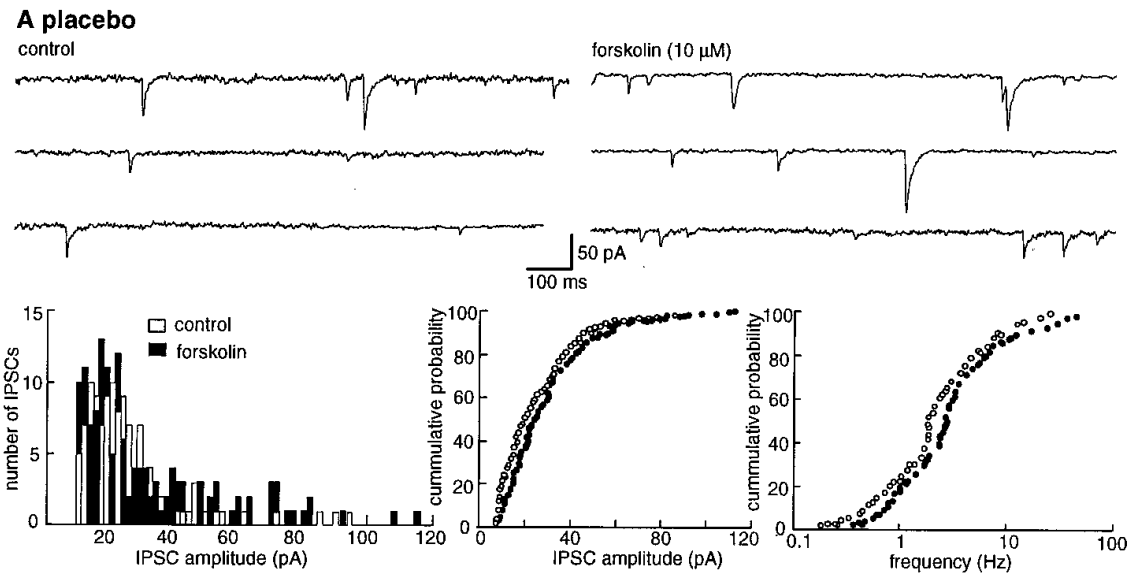

B withdrawn

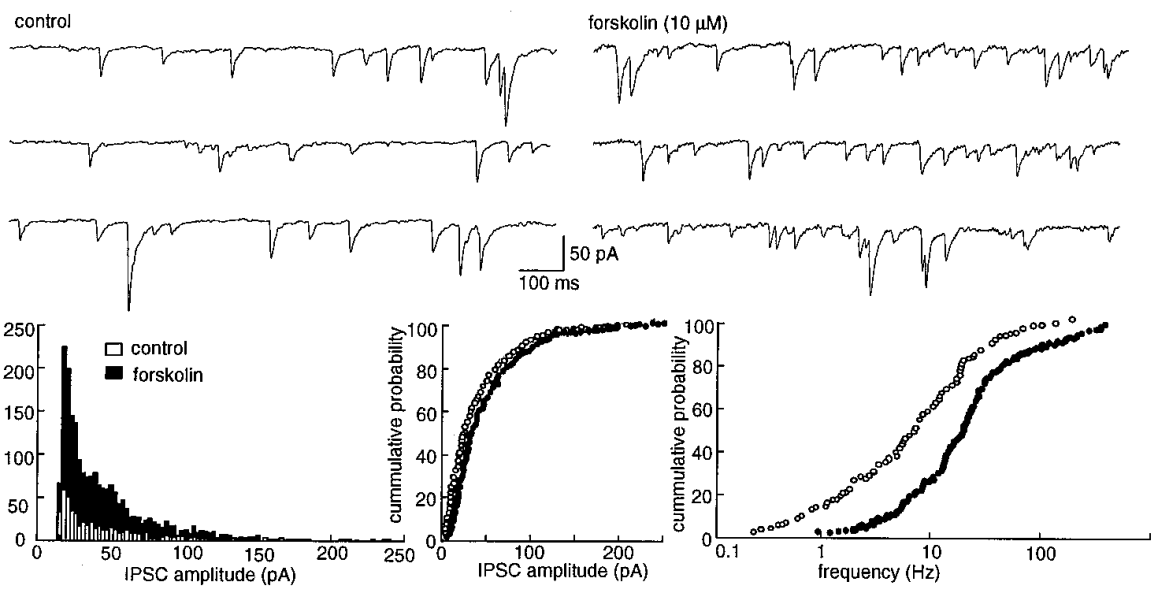

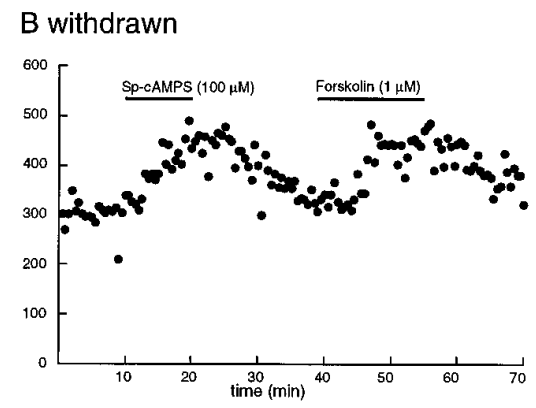

Figure 4. The cAMP analog Sp-cAMPS is more effective in increasing the IPSC in slices from morphine-withdrawn slices than placebo controls. The amplitude of the electrically evoked IPSC is plotted as a function of time. $A$, Top, Example of one experiment in a slice taken from a control animal. The cAMP analog Sp-cAMPS $(100 \mu \mathrm{M})$ has no effect on the amplitude of the IPSC, whereas a low concentration of forskolin $(1 \mu \mathrm{M})$ increased the amplitude of the IPSC. Bottom, Average of four such experiments in slices taken from four different animals. The average amplitude of IPSCs over the first $5 \mathrm{~min}$ was used to normalize the data. $B$, Top, An experiment in a single cell taken from a morphine-treated animal. In this case, cAMP analog Sp-cAMPS caused an increase in the IPSC that was about the same as that induced by forskolin. Bottom, Normalized and averaged results from four experiments.
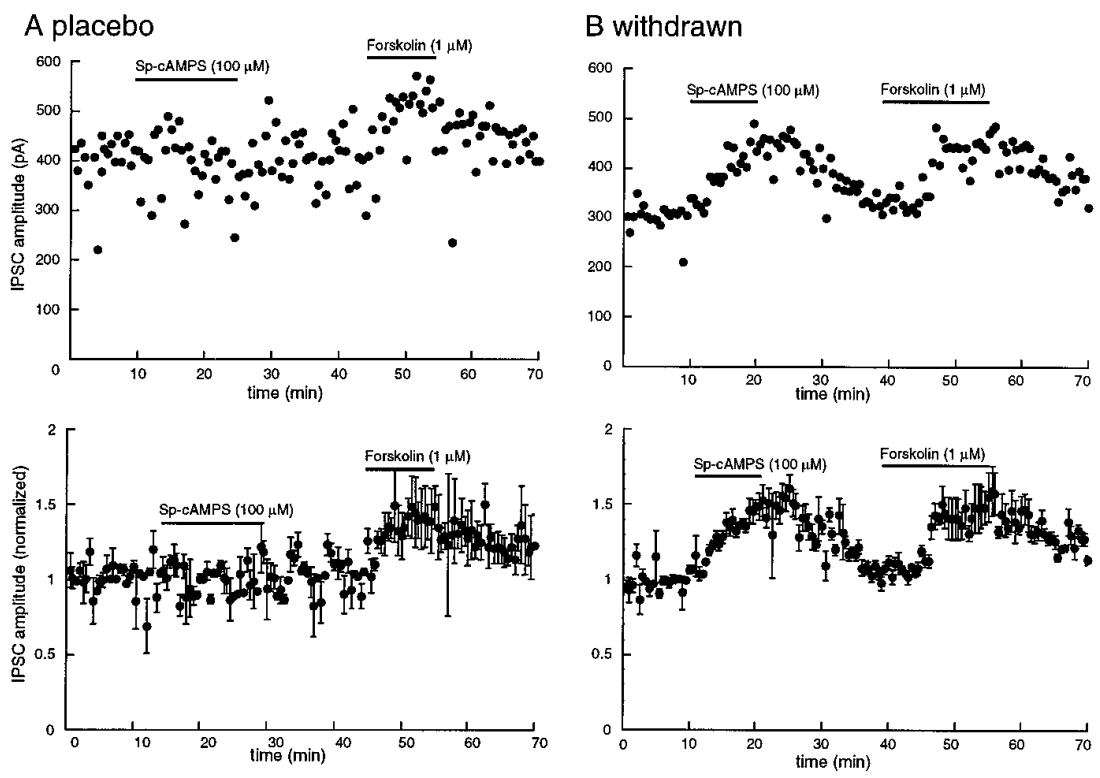

of adenylyl cyclase activity was different in the two groups of tissues. Although this compound caused an initial depression of the IPSC, continued application resulted in a large increase in the IPSC, such that the result was not interpretable. Initial experiments with the nonselective phosphatase inhibitor tautomycin (100 nM) were carried out to determine the role of phosphatases.
Tautomycin caused a transient augmentation of the IPSC followed by total suppression, limiting interpretation of the results.

\section{DISCUSSION}

Morphine decreased the amplitude of the $\mathrm{GABA}_{\mathrm{A}}$-mediated IPSC in the VTA. After chronic treatment with morphine, there 

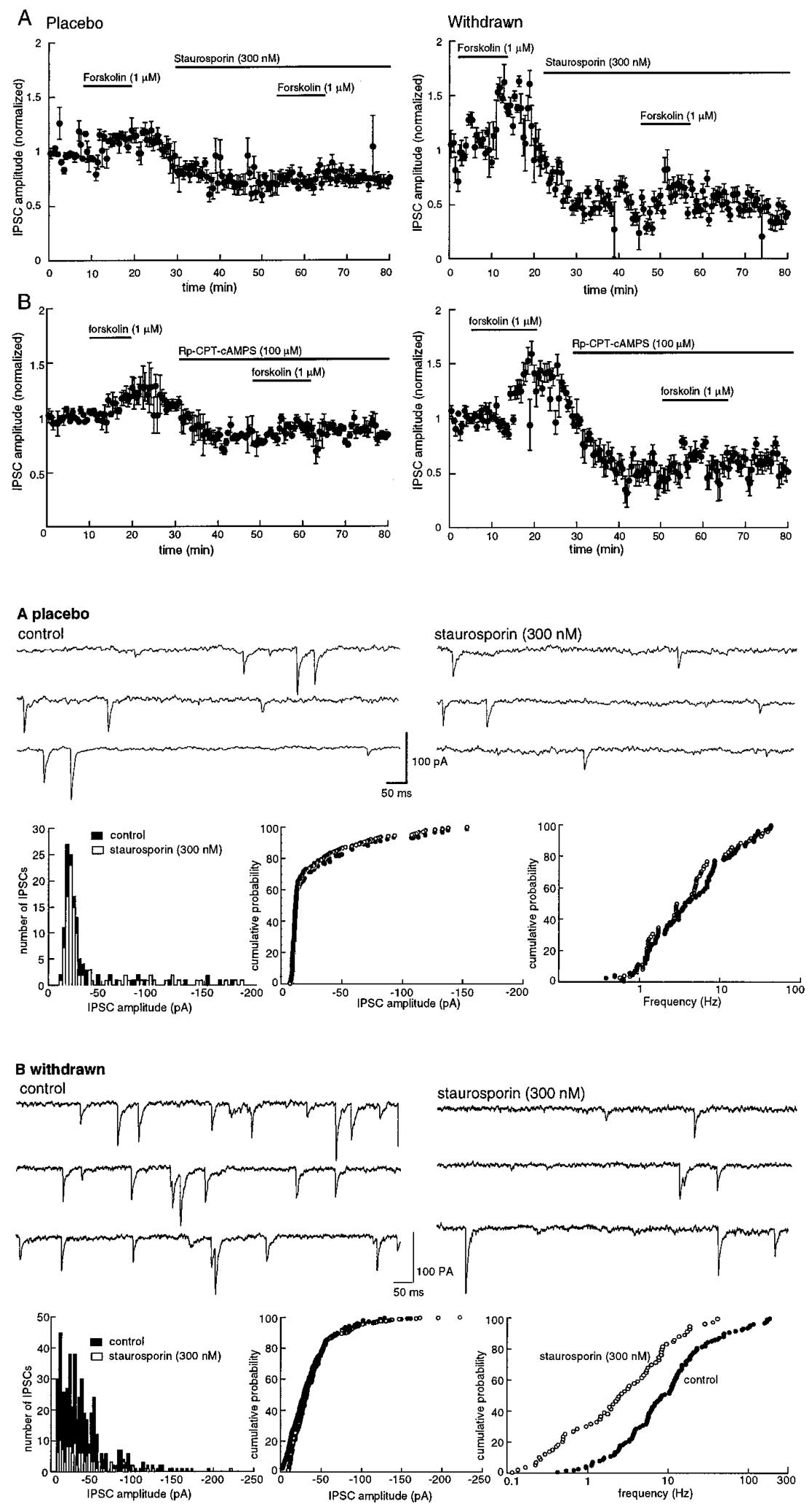

Figure 5. The protein kinase inhibitors staurosporine $(A, 300 \mathrm{~nm})$ and Rp-CPT-cAMPS $(B, 100 \mu \mathrm{M})$ decreased the IPSC in slices from both placebo- and morphine-treated animals. The inhibition is greater in morphine-withdrawn slices. In all plots, the IPSC amplitudes were normalized to the average determined over the first $5 \mathrm{~min}$ of the experiment. Plots on the left are from control animals (Placebo), and plots on the right are from morphine-treated animals (Withdrawn). $A$, A low concentration of forskolin $(1 \mu \mathrm{M})$ increased the amplitude of the IPSC, and staurosporine decreased the amplitude of the IPSC and blocked the forskolin-induced augmentation $(n=4)$. The plot labeled Withdrawn is the same experiment as shown at the left in slices taken from four morphine-treated animals. The inhibition induced by staurosporine is significantly larger than in controls $(p<0.05) . B$, The cAMP analog Rp-CPT-cAMPS, a cAMP-dependent kinase inhibitor, produced a greater inhibition of the amplitude of IPSCs in slices from both withdrawn slices than placebo controls ( $n=4$ for each group; $p<$ $0.05)$. The same protocol was used as described for $A$.
Figure 6. The frequency of mIPSCs is decreased by staurosporine $(300 \mathrm{nM})$. The decrease is greater in morphine-withdrawn slices than in controls. $A$, Experiment from a cell in a slice from a control animal. Top traces show the occurrence of spontaneous IPSCs in control (left) and after superfusion with staurosporine (300 nM, right). The three plots below the traces show an amplitude histogram (left), a cumulative probability plot of the amplitude (middle), and a cumulative probability plot of the frequency of spontaneous IPSCs from the same cell shown above. Staurosporine had little effect on the rate and amplitude of the spontaneous IPSCs. $B$, Illustration of the same experiment in a cell from a morphine-withdrawn slice. The initial rate of activity was higher, and staurosporine induced a significant decrease in the rate of spontaneous IPSCs $(p<0.05)$. was some tolerance to opioids; however, the ability of opioids to inhibit release was maintained. The results of the present study demonstrate that during the initial period after withdrawal from prolonged morphine exposure an upregulation of the adenylyl cyclase cascade resulted in an increase in the probability of GABA release from terminals that mediate $\mathrm{GABA}_{\mathrm{A}}$ IPSCs. This may result from an adaptive process at a point beyond the opioid receptor because all experiments were carried out in the absence of morphine. The persistence of the augmented release after withdrawal of morphine for periods of up to $8 \mathrm{hr}$ also suggests that this adaptive mechanism was not dependent on opioid receptor activation. It is important to determine how long the augmented 
release persists because the release of $G A B A$ acting at $G_{A B A}$ receptors was depressed 1 week after termination of morphine treatment (Bonci and Williams, 1996). Our working hypothesis is that the $\mathrm{GABA}_{\mathrm{A}^{-}}$and $\mathrm{GABA}_{\mathrm{B}}$-mediated synaptic inhibition results from separate sets of terminals. The augmented $\mathrm{GABA}_{\mathrm{A}}$ mediated inhibition described here may be a measure of acute withdrawal from opioids that is relatively short-lived (1-3 d). The depression of $\mathrm{GABA}_{\mathrm{B}}$-mediated inhibition, however, is a longterm effect of withdrawal from chronic drug treatment that is either not present or occluded by the augmented $\mathrm{GABA}_{\mathrm{A}}$ tone early in withdrawal. In fact, during acute withdrawal from morphine there may be diffusion of GABA between terminals mediating the two synaptic events, as has been reported under certain conditions in the hippocampus (Isaacson et al., 1993).

\section{Upregulation of adenylyl cyclase/cAMP-dependent pathway}

The present observations are consistent with reports of an increased activity of adenylyl cyclase and cAMP-dependent protein kinase during acute withdrawal from chronic morphine treatment in cell lines and in several brain areas (Sharma et al., 1975; Nestler and Tallman, 1988) (for review, see Johnson and Flemming, 1989; Nestler et al., 1993). Although biochemical experiments specifically in the VTA have not demonstrated a rise in cyclase activity after chronic morphine treatment, the heterogeneity of cell types in the VTA limits the interpretation of negative data (Terwilliger et al., 1991). The present study focused on a synapse known to be opioid-sensitive such that a localized upregulation of the cAMP system in a small portion of neurons and/or terminals could be detected.

There were two primary observations that indicate an upregulation of the cAMP-dependent pathway after chronic morphine treatment. The first was that forskolin caused a significantly larger increase in $\mathrm{GABA}_{\mathrm{A}}$ IPSCs in slices from morphine-treated animals than controls. This effect was mediated by adenylyl cyclase because dideoxyforskolin, an inactive analog that does not activate adenylyl cyclase, did not have any effect. The concentration response to forskolin resulted in an increase in the maximum response rather than a change in the $\mathrm{EC}_{50}$. The augmented maximum effect of forskolin could result from a number of mechanisms, including an increase in the $V_{\max }$ of adenylyl cyclase, a decline in cAMP-dependent phosphodiesterase activity, or an upregulation of downstream cAMP-dependent processes. There is evidence in the literature that all three mechanisms can occur in response to chronic morphine treatment (Yu et al., 1990; Self and Nestler, 1995). The increased sensitivity to cAMP during withdrawal seems selective as suggested by the experiments with the protein kinase $\mathrm{C}$ activator PDBU. Although PDBU increased the amplitude of $\mathrm{GABA}_{\mathrm{A}}$ IPSCs, the increase was not different in slices from control and morphine-treated animals.

The second observation was that agents that interact directly with cAMP-dependent kinase had quantitatively different effects in morphine-withdrawn slices. The stable cAMP analog SpcAMPS caused only a small increase in the IPSC in control (9\%) but had a significantly greater effect in slices from morphinetreated animals (46\%). This experiment suggests that cAMPdependent kinase activity was increased during acute withdrawal. In addition, the results with the kinase inhibitors Rp-CPT-cAMPS and staurosporine suggested that the basal kinase activity was elevated in slices from morphine-treated animals. Such an upregulation of basal and stimulated kinase activity after chronic morphine treatment has been reported in cell lines and various brain areas (Duman et al., 1988; Nestler and Tallman, 1988; Nestler et al., 1993).

\section{Morphine withdrawal}

There are numerous examples of an increased firing rate after withdrawal of opioids in experiments done in vivo (Fry et al., 1980; Johnson and Duggan, 1981). The identification of cellular mechanisms of morphine withdrawal has proven difficult in brain slices (Christie et al., 1987; Wimpey et al., 1989) and in cell lines (Kennedy and Henderson, 1991, 1992). That is, withdrawal from morphine has not been observed to cause a rebound effect on either potassium or calcium conductances. Recently, a subpopulation of neurons in the periaqueductal gray (PAG) from morphine-dependent animals has been observed to be strongly depolarized by the addition of naloxone to the superfusion solution (Chieng and Christie, 1996). This depolarization appeared to be a direct because it was not affected by a combination of neurotransmitter receptor antagonists or tetrodotoxin. Although acute activation of opioid receptors on neurons in the PAG has been shown to increase potassium conductance (Chieng and Christie, 1994), the depolarization induced by naloxone in tissue from morphine-dependent animals resulted from a decrease in potassium conductance (which may be a reversal of the effect of morphine contained in the superfusion solution) and another unidentified mechanism.

Reports on the excitability of neurons in the LC during morphine withdrawal were dependent on the conditions of the experiment. In in vivo experiments, systemic injection of naloxone caused a marked increase in firing rate in morphine-treated animals (10-fold) that was largely blocked by glutamate receptor antagonists (Tung et al., 1990; Akaoka and Aston-Jones, 1991). In brain slices, the firing rate of LC neurons from morphine-treated animals has been reported to be unchanged (Andrade et al., 1983) or increased twofold over controls (Kogan et al., 1992). An increased sensitivity of LC cells to cAMP analogs after chronic morphine treatment was suggested to account for the increased firing rate (Kogan et al., 1992); however, experiments were not done after blockade of glutamate or other neurotransmitter receptors. The combination of results obtained with in vivo experiments and the increased probability of transmitter release from opioid-sensitive terminals observed in the present study suggest that an excitatory synaptic mechanism may be important during morphine withdrawal.

\section{Significance}

Whereas the firing rate of dopamine cells in the VTA was increased acutely by morphine in vivo (Gysling and Wang, 1983), during withdrawal from morphine, activity was profoundly decreased (Diana et al., 1995). In addition, many of the signs and symptoms of morphine withdrawal were attenuated by activation of $\mathrm{D}_{2}$ dopamine receptors in the nucleus accumbens, suggesting that dopamine tone was decreased during withdrawal (Harris and Aston-Jones, 1994). We suggest that the withdrawal inhibition of dopamine cell firing and decreased dopamine tone in the nucleus accumbens results from augmented GABA tone. Results with mIPSCs suggest that the expression of this form of withdrawal occurred at the terminals of GABA interneurons. The physiological consequences resulting from the link between the acute effects of opioids and cAMP mechanisms has been difficult to demonstrate; however, the interaction among transmitter release, cAMP mechanisms, and chronic opioid treatment may prove to be a general observation. Given the number of opioid-sensitive ter- 
minals, both excitatory and inhibitory, the augmented transmitter release after chronic morphine treatment has the potential for widespread consequences.

\section{REFERENCES}

Aghajanian GK (1978) Tolerance of locus coeruleus neurons to morphine and suppression of withdrawal response by clonidine. Nature 276:186-187.

Akaoka H, Aston-Jones G (1991) Opiate withdrawal-induced hyperactivity of locus coeruleus neurons is substantially mediated by augmented excitatory amino acid input. J Neurosci 11:3830-3839.

Andrade R, Vandermaelen CP, Aghajanian GK (1983) Morphine tolerance and dependence in the locus coeruleus: single cell studies in brain slices. Eur J Pharmacol 91:161-165.

Bonci A, Williams JT (1996) A common mechanism mediates long-term changes in synaptic transmission after chronic cocaine and morphine. Neuron 16:631-639.

Bozarth MA, Wise RA (1981) Intracranial self-administration of morphine into the ventral tegmental area in rats. Life Sci 28:551-555.

Cameron DL, Williams JT (1993) Dopamine D1 receptors facilitate transmitter release. Nature 366:344-347.

Cameron DL, Williams JT (1994) Cocaine inhibits GABA release in the VTA through endogenous 5-HT. J Neurosci 14:6763-6767.

Chavkin C, Goldstein A (1984) Opioid receptor reserve in normal and morphine-tolerant guinea pig ilium myenteric plexus. Proc Natl Acad Sci USA 81:7253-7257.

Chieng B, Christie MJ (1994) Hyperpolarization by opioids acting on $\mu$-receptors of a subpopulation of rat periaqueductal gray neurones in vitro. Br J Pharmacol 113:121-128.

Chieng B, Christie MJ (1996) Local opioid withdrawal in rat single periaqueductal gray neurons in vitro. J Neurosci 16:7128-7136.

Christie MJ, Williams JT, North RA (1987) Cellular mechanisms of opioid tolerance: studies in single brain neurons. Mol Pharmacol 32:633-638.

Cohen GA, Doze VA, Madison DV (1992) Opioid inhibition of GABA release from presynaptic terminal of rat hippocampal interneurons. Neuron 9:325-335

Dianan M, Pistis M, Muntoni A, Gessa G (1995) Profound decrease of mesolimbic dopaminergic neuronal activity in morphine-withdrawn rats. J Pharmacol Exp Ther 272:781-785.

Duman R, Tallman J, Nestler E (1988) Acute and chronic opiateregulation of adenylate cyclase in brain: specific effects in locus coeruleus. J Pharmacol Exp Ther 246:1033-1039.

Fry JP, Herz A, Zieglgansberger W (1980) A demonstration of naloxoneprecipitated opiate withdrawal on single neurons in the tolerance/ dependent rat brain. Br J Pharmacol 68:585-592.

Gysling K, Wang RY (1983) Morphine-induced activation of A10 dopamine neurons in the rat. Brain Res 277:119-127.

Harris GC, Aston-Jones G (1994) Involvement of D2 dopamine receptors in the nucleus accumbens in the opiate withdrawal syndrome. Nature 371:155-157.

Isaacson JS, Solis JM, Nicoll RA (1993) Local and diffuse synaptic actions of GABA in the hippocampus. Neuron 10:165-175.

Johnson SM, Duggan AW (1981) Tolerance and dependence of dorsal horn neurones of the cat: the role of the opiate receptors of the substantia gelatinosa. Neuropharmacology 20:1033-1038.

Johnson SM, Flemming W (1989) Mechanisms of cellular adaptive sensitivity changes: application to opioid tolerance and dependence. Pharmacol Rev 41:435-488.

Johnson SW, North RA (1992a) Opioids excite dopamine neurons by hyperpolarization of local interneurons. J Neurosci 12:483-488.

Johnson SW, North RA (1992b) Two types of neurone in the rat ventral tegmental area and their synaptic inputs. J Physiol (Lond) 450:455-468.

Johnson SW, Mercuri NB, North RA (1992) 5-Hydroxytryptamine ${ }_{1 \mathrm{~B}}$ receptors block the $\mathrm{GABA}_{\mathrm{B}}$ synaptic potential in rat dopamine neurons. J Neurosci 12:2000-2006.
Kennedy C, Henderson G (1991) $\mu$-Opioid receptor inhibition of calcium current: development of homologous tolerance in single SH-SY5Y cells after chronic exposure to morphine in vitro. Mol Pharmacol 40:1000-1005.

Kennedy C, Henderson G (1992) Chronic exposure to morphine does not induce dependence at the level of the calcium channel current in human SH-SY5Y cells. Neuroscience 49:937-944.

Kogan J, Nestler E, Aghajanian G (1992) Elevated basal firing rates and enhanced responses to $8 \mathrm{Br}$-cAMP in locus coeruleus neurons in brain slices from opiate-dependent rats. Eur J Pharmacol 211:47-53.

Law PY, Hom DS, Loh HH (1982) Loss of opiate receptor activity in neuroblastoma $\times$ glioma NG108-15 hybrid cells after chronic opiate treatment: a multiple-step process. Mol Pharmacol 22:1-4.

Madison DV, Nicoll RA (1988) Enkephalin hyperpolarizes interneurones in the rat hippocampus. J Physiol (Lond) 398:123-130.

Mennerick S, Zorumski CF (1995) Paired-pulse modulation of fast excitatory synaptic currents in microcultures of rat hippocampal neurons. J Physiol (Lond) 488:85-101.

Nestler E, Tallman J (1988) Chronic morphine treatment increases cyclic AMP-dependent protein kinase activity in the rat locus coeruleus. Mol Pharmacol 33:127-132.

Nestler EJ, Hope BT, Widnell KL (1993) Drug addiction: a model for the molecular basis of neural plasticity. Neuron 11:995-1006.

Nicoll RA, Alger BE, Jahr CE (1980) Enkephalin blocks inhibitory pathways in the vertebrate CNS. Nature 287:22-25.

Puttfarcken PS, Werling LL, Cox BM (1988) Effects of chronic morphine exposure on opioid inhibition of adenylyl cyclase in $7315 \mathrm{c}$ cell membranes: a useful model for the study of tolerance at $\mu$ opioid receptors. Mol Pharmacol 33:520-527.

Rosenmund C, Carr DW, Bergeson SE, Nilaver G, Scott JD, Westbrook GL (1994) Anchoring of protein kinase A is required for modulation of AMPA/kainate receptors on hippocampal neurons. Nature 368:853-856.

Salin PA, Malenka RC, Nicoll RA (1996) Cyclic AMP mediates a presynaptic form of LTP at cerebellar parallel fiber synapses. Neuron 16:797-803.

Self DW, Nestler EJ (1995) Molecular mechanisms of drug reinforcement and addiction. Annu Rev Neurosci 18:46395.

Sharma SK, Klee WA, Nirenberg M (1975) Dual regulation of adenylate cyclase accounts for narcotic dependence and tolerance. Proc Natl Acad Sci USA 72:3092-3096.

Terwilliger RZ, Beitner-Johnson D, Sevarino KA, Crain SM, Nestler EJ (1991) A general role for adaptations in G-proteins and the cyclic AMP system in mediating the chronic actions of morphine and cocaine on neuronal function. Brain Res 548:100-110.

Tung CS, Grenhoff J, Svensson TH (1990) Morphine withdrawal responses of rat locus coeruleus neurons are blocked by an excitatory amino-acid antagonist. Acta Physiol Scand 138:581-582.

Wimpey TL, Chavkin C (1991) Opioids activate both an inward rectifier and a novel voltage-gated potassium conductance in the hippocampal formation. Neuron 6:281-289.

Wimpey TL, Opheim KE, Chavkin C (1989) Effects of chronic morphine administration on the mu and delta opioid responses in the CA1 region of the rat hippocampus. J Pharmacol Exp Ther 251:405-411.

Wise RA, Rompre PP (1989) Brain DA and reward. Annu Rev Psychol 40:191-225.

Wu Y, Mercuri NB, Johnson SW (1995) Presynaptic inhibition of $\gamma$-aminobutyric acid-B-mediated synaptic current by adenosine recorded in vitro in midbrain dopamine neurons. J Pharmacol Exp Ther 273:576-581.

Yu VC, Eiger S, Duan DS, Lameh J, Sadee W (1990) Regulation of cyclic AMP by the $\mu$-opioid receptor in human neuroblastoma $\mathrm{SH}$ SY5Y cells. J Neurochem 55:1390-1396. 